\title{
QuANTIFICAÇÃo de Sorgoleone EM Extratos E RAÍzes de Sorgo sob Diferentes Períodos de Armazenamento ${ }^{1}$
}

\author{
Quantification of Sorgoleone in Sorghum Extracts and Roots under Different Storage Periods
}

FRANCO, F.H.S. ${ }^{2}$, MACHADO, Y. ${ }^{3}$, TAKAHASHI, J.A. ${ }^{3}$, KARAM, D. ${ }^{4}$ e GARCIA, Q.S. ${ }^{5}$

\begin{abstract}
RESUMO - Neste trabalho, foi realizada a purificação, a obtenção do padrão de sorgoleone $\left(2\right.$ - hidroxi - 5 - metoxi - $3-\left[\left(8^{\prime} Z, 11^{\prime} Z\right)-8^{\prime}, 11^{\prime}, 14^{\prime}\right.$-pentadecatrieno]-p-benzoquinona) e a quantificação desse marcador em raizes primárias de sorgo. As sementes de sorgo foram desinfectadas, colocadas em placas gerbox opacas e acondicionadas em câmara de germinação a $30{ }^{\circ} \mathrm{C}$ durante sete dias no escuro. Posteriormente, a extração foi feita mergulhando-se as raízes por $5 \mathrm{~min}$ em solução de ácido acético glacial em diclorometano 0,0025\% v/v. A quantificação de sorgoleone nos extratos obtidos foi feita por cromatografia líquida de alta eficiência (HPLC), utilizando-se uma curva de calibração. Foi avaliado o efeito do armazenamento de extratos e de raizes, utilizando-se três repetições para cada tratamento. Os extratos de raizes recém-coletadas foram armazenados a $-20{ }^{\circ} \mathrm{C}$ por $0,1,3,5,7,14 \mathrm{e}$ 21 dias. As raizes foram coletadas e imediatamente congeladas $\left(20^{\circ} \mathrm{C}\right)$ e armazenadas pelo mesmo periodo, quando foram submetidas à extração. Não foi observada diferença significativa entre a quantidade de sorgoleone em extratos armazenados e a de não armazenados, sendo observado o mesmo resultado em extratos obtidos de raizes frescas e armazenadas. Os resultados obtidos mostram que o armazenamento por até 21 dias não altera o conteúdo de sorgoleone nos extratos.
\end{abstract}

Palavras-chave: Sorghum bicolor, BR 007, alelopatia, purificação, padronização.

\begin{abstract}
Sorgoleone (2 - hydroxy - 5- methoxy - 3-[(8'Z, 11'Z)-8', 11',14'-pentadecatriene]-pbenzoquinone) was purified, identified by NMR, and quantified in primary roots of sorghum. The seeds were disinfected and stored in dark gerbox plates inside germination chambers at $30^{\circ} \mathrm{C}$ for seven days. Extraction was made by immersing the roots during 5 minutes in a glacial acetic acid/ dichloromethane solution 0, 0025\% v/v. Sorgoleone quantification in the extracts was achieved by using a calibration curve made with the data obtained through High Performance Liquid Chromatography (HPLC). The effect of storing the extracts and roots was verified using three repetitions. The extracts of freshly collected roots were stored at $-20^{\circ} \mathrm{C}$ for $0,1,3,5,7,14$ and 21 days. No significant difference was observed between the amount of sorgoleone present in the stored and non-stored extracts. The same result was found for the extracts obtained from fresh and stored roots. The results obtained showed that storage up to 21 days does not alter the content of sorgoleone in the extracts.
\end{abstract}

Keywords: Sorghum bicolor, BR 007, allelopathy, purification, standardization.

\section{INTRODUÇÃO}

A planta de sorgo, Sorghum spp. (Poaceae), como se apresenta hoje, é um produto da intervenção do homem, que vem transformando-a de acordo com as suas necessidades. É uma planta $\mathrm{C}_{4}$, de dias curtos, com elevada taxa fotossintética e capacidade de tolerar déficit hídrico, o que a torna uma alternativa importante para plantio em regiões quentes e secas (Magalhães et al., 2009).

No Brasil, a cultura do sorgo apresentou avanço significativo nos últimos anos; segundo

1 Recebido para publicação em 17.2.2011 e aprovado em 16.3.2011.

2 Pós-Graduação em Biologia Vegetal, Universidade Federal de Minas Gerais - UFMG, ${ }^{3}$ Dep. de Química, ICEX, UFMG, ${ }^{4}$ Embrapa Milho e Sorgo, Caixa Postal 285, 35701-970 Sete Lagoas-MG; <karam@cnpms.embrapa.br>; ${ }^{5}$ Dep. de Botânica, ICB, UFMG, Caixa Postal 486, 31270-970 Belo Horizonte, MG, <queilagarcia@gmail.com>. 
Rodrigues (2009), esse crescimento é explicado pelo alto potencial de produção de grãos e matéria seca da cultura, além da sua extraordinária capacidade de suportar estresses ambientais. As zonas de adaptação da cultura se concentram na região Sul em plantios de verão, no Brasil Central em sucessão a plantios de verão e no Nordeste em plantios no semiárido (Tardin et al., 2009). Atualmente, o cultivo do sorgo ocorre sobretudo em plantios de sucessão em algumas regiões, com destaque para os Estados de São Paulo, Goiás, Mato Grosso, Mato Grosso do Sul e para a região do Triângulo Mineiro, onde se concentram aproximadamente $90 \%$ do sorgo granífero plantado no Brasil (Tardin et al., 2009).

Algumas espécies do gênero Sorghum, como S. bicolor, S. sudanense, S. halepense e S. vulgare, possuem considerável potencial alelopático (Panasiuk et al., 1986; Einhellig \& Rasmussen, 1989). Resíduos de sorgo deixados no solo são capazes de prejudicar o crescimento tanto da parte aérea quanto radicular de plantas de soja (Olibone et al., 2006). Além disso, a palha do sorgo sobre o solo, associada à utilização de herbicidas, é capaz de otimizar a eliminação de plantas daninhas, como Ipomoea grandifolia e Commelina benghalensis (Correia et al., 2005 ).

Os primeiros trabalhos identificaram compostos hidrofilicos, principalmente fenólicos, como possiveis responsáveis pelos efeitos alelopáticos; entretanto, esses compostos são encontrados em várias outras plantas e estão ligados a muitas outras funções (Guenzi et al., 1967; Lehle \& Putnam, 1983; Alsaadawi et al., 1986; Panasiuk et al., 1986). Os estudos de Netzly \& Butler (1986) revelaram a presença de componentes hidrofóbicos em exsudatos de raizes de 25 cultivares de $S$. bicolor. Essa exsudação constituía-se de gotículas amareladas localizadas próximas ao ápice dos pelos radiculares, extraídas com clorofórmio, e mostrouse um potente inibidor do desenvolvimento de outras plantas (Netzly \& Butler, 1986; Einhellig \& Souza, 1992; Souza et al., 1999; Trezzi et al., 2005a).

O exsudato hidrofóbico das raízes de sorgo foi caracterizado quimicamente por ressonância magnética nuclear (RMN) de hidrogênio e de carbono-13 e constatou-se a presença de dois componentes majoritários: um deles era muito instável, transformando-se rapidamente no outro. Eles foram identificados, respectivamente, como uma di-idroquinona e sua forma oxidada, 2 - hidroxi, 5 - metoxi, 3 - [ (8'Z,11'Z) - 8',11',14'-pentadecatrieno]-p-benzoquinona (Chang et al., 1986). O composto em sua forma oxidada recebeu o nome de sorgoleone (Netzly et al., 1988) e é atualmente um dos aleloquímicos mais bem estudados (Uddin et al., 2010; Dayan et al., 2010). Devido à sua hidrofobicidade, é esperado que tenha forte adsorção ao solo, especialmente à matéria orgânica e a outros componentes hidrofóbicos, propriedades ideais para a atividade biológica de um aleloquímico (Dayan et al., 2010).

A quantidade de sorgoleone em extratos obtidos das raízes de sorgo tem sido analisada por meio da pureza relativa, comparando-se a quantidade de sorgoleone em relação a outras substâncias que eventualmente são detectadas durante a eluição do extrato em HPLC (Czarnota et al., 2003b; Trezzi et al., 2005b). Em muitos estudos, a extração de sorgoleone tem sido feita a partir de raízes recém-coletadas, e o extrato é usualmente armazenado em baixas temperaturas antes da sua utilização em testes de atividade e do seu fracionamento (Einhelling \& Souza, 1992; Rasmussen et al., 1992; Nimbal et al., 1996; Souza et al., 1999; Kagan et al., 2003; Czarnota et al., 2003b; Hej1 $\&$ Koster, 2004). Alguns estudos mostram que o armazenamento de órgãos vegetais antes da extração pode acarretar alterações no extrato final obtido (Palta et al., 1977; Olien \& Smith, 1977; Chen \& Gusta, 1978; Weiser et al., 1990; Murai \& Yoshida, 1998). Além disso, as condições de armazenamento de extratos vegetais podem influenciar na estabilidade e degradação dos compostos químicos presentes (Srivastava et al., 2007; Tabart et al., 2007).

Tendo em vista a expansão crescente da cultura do sorgo no Brasil e sua conhecida atividade alelopática, este estudo teve como objetivo gerar conhecimentos básicos para o desenvolvimento de produtos naturais, alternativos a herbicidas. Para isso, procedeu-se à purificação para obtenção do padrão de sorgoleone e sua quantificação, bem como avaliou-se o efeito do armazenamento de raízes e de extratos sobre a concentração final de sorgoleone. 


\section{MATERIAL E MÉTODOS}

\section{Material botânico}

Foram utilizadas sementes do acesso de sorgo BR 007A, cedidas pela Empresa Brasileira de Pesquisa Agropecuária - Centro Nacional de Pesquisa em Milho e Sorgo (Embrapa Milho e Sorgo).

\section{Obtenção dos extratos}

As sementes foram desinfectadas com solução de hipoclorito de sódio $2,5 \%$ durante 10 min e posteriormente lavadas três vezes com água destilada, sendo colocadas em placas gerbox opacas forradas com papel-filtro, utilizando-se uma amostragem de 15 sementes por placa. O papel-filtro foi umedecido com $3 \mathrm{~mL}$ de água destilada e $3 \mathrm{~mL}$ de solução de nistatina $1 \%$. As sementes foram cobertas com outra camada de papel-filtro, e as placas, colocadas em câmara de germinação a $30^{\circ} \mathrm{C}$ durante sete dias no escuro.

Após o crescimento, as raízes de sorgo foram destacadas da parte aérea e pesadas, para determinação da massa fresca. Para a extração, as raízes foram mergulhadas por 5 min em solução de ácido acético glacial em diclorometano $0,0025 \% \mathrm{v} / \mathrm{v}$. A solução resultante foi filtrada em algodão e o solvente retirado em evaporador rotatório a $30{ }^{\circ} \mathrm{C}$. O material restante foi ressuspenso com diclorometano, e a solução resultante foi retirada com pipeta de Pasteur, colocada em frasco de $10 \mathrm{~mL}$ e deixada em capela à temperatura ambiente até a evaporação total dos solventes. Posteriormente, foi obtida a massa seca dos extratos.

\section{Purificação do extrato e obtenção do padrão}

Como não há sorgoleone puro disponivel comercialmente, foi necessária a sua purificação para utilização como padrão. A extração foi feita a partir de cerca de 1.350 raízes (30,21 g de massa fresca), das quais foram obtidos 130,07 mg de extrato.

Foi utilizada a técnica de cromatografia em coluna aberta (CC) para o fracionamento do extrato obtido, tendo-se, como fase estacionária, sílica-gel e, como eluentes, hexano, clorofórmio e metanol. A quantidade de sílica utilizada foi medida tendo-se como parâmetro a altura da coluna (Cannell, 1998). Durante o fracionamento, foram recolhidas 153 frações de $40 \mathrm{~mL}$, as quais foram submetidas à secagem sob pressão reduzida em evaporador rotatório a $30^{\circ} \mathrm{C}$. Após análise por cromatografia em camada delgada (CCD), essas frações foram combinadas em 15 grupos de acordo com a semelhança dos perfis cromatográficos, sendo obtida a massa seca de cada grupo.

Dentre os 15 grupos obtidos, o material do grupo 5, devido à sua coloração arroxeada, semelhante à descrita na literatura para o sorgoleone, foi solubilizado em clorofórmio deuterado e analisado por RMN, sendo identificado quimicamente como sorgoleone. Em seguida, foi feita uma injeção em HPLC, cromatógrafo Shimadzu LC10A series, utilizando um detector de arranjo de diodos SPD MXAvp, conectado a uma pré-coluna e a uma coluna Supelco de octadecilsiloxano $(250 \times 46 \mathrm{~mm}$; $5 \mu \mathrm{m}$ de diâmetro da partícula), sendo a fase móvel acetonitrila ( $75 \%$ ) na bomba B e solução de ácido acético glacial $\left(0,435 \mathrm{~mol} \mathrm{~L}^{-1} 25 \%\right)$ na bomba A. O fluxo usado foi de $2,0 \mathrm{~mL} \mathrm{\textrm {min } ^ { - 1 }}$ durante $18 \mathrm{~min}$. O cromatograma obtido mostrou que o material presente na combinação 5 apresentava pequena quantidade de outras substâncias além do sorgoleone.

Dessa forma, foi necessária uma segunda purificação para o isolamento do sorgoleone (Figura 1). A amostra foi fracionada em coluna aberta contendo sílica-flash com eluição em clorofórmio/acetato de etila 5\%, usando-se pressão. Foram recolhidas 41 frações de $10 \mathrm{~mL}$, que foram secas em capela à temperatura ambiente e, em seguida, submetidas à análise por CCD com eluição em clorofórmio/ acetato de etila (9:1). A partir do perfil cromatográfico obtido, as frações foram combinadas, resultando em cinco combinações finais, e a fração com características semelhantes às do sorgoleone foi injetada em HPLC, para quantificação de sorgoleone nessas frações. Foram injetadas cinco amostras da fração (20 $\mu \mathrm{L}$ cada em metanol) nas concentrações de $600,530,460,390$ e $320 \mu \mathrm{g} \mathrm{mL}^{-1}$. Com os dados obtidos a partir dos cromatogramas (Tabela 1), chegou-se à equação: 


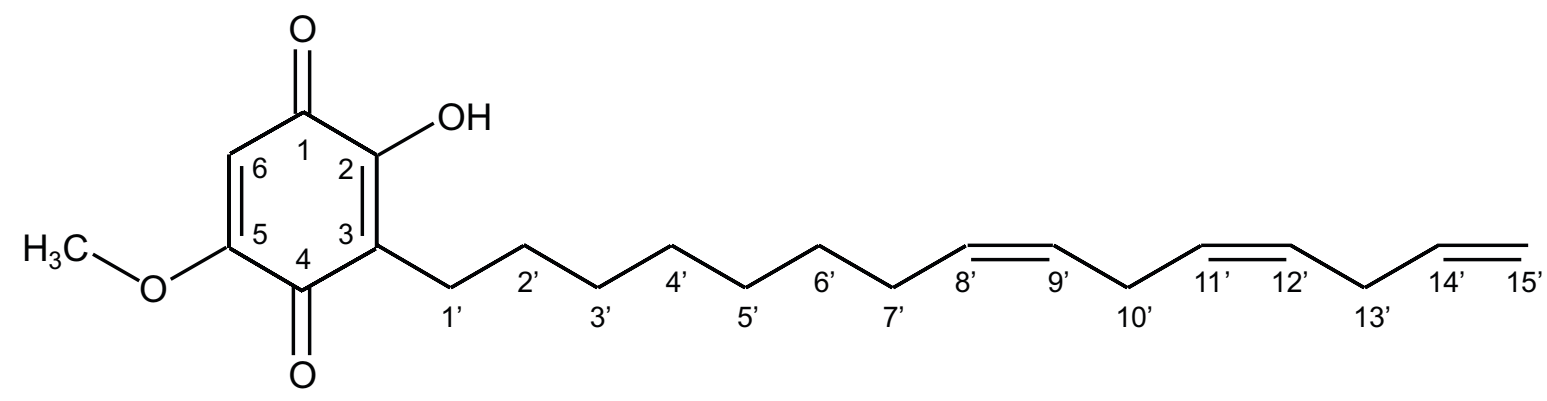

Figura 1 - Estrutura da molécula de sorgoleone.

Tabela 1 - Concentração, área dos picos de sorgoleone, pureza relativa e desvio- padrão das amostras injetadas para dedução da equação da curva de calibração (média de três injeções para cada concentração)

\begin{tabular}{|c|c|c|r|c|}
\hline $\begin{array}{c}\text { Concentração } \\
\left(\mu \mathrm{g} \mathrm{mL} \mathrm{mL}^{-1}\right)\end{array}$ & Área & $\begin{array}{c}\text { Pureza } \\
\text { relativa }\end{array}$ & $\begin{array}{c}\text { Desvio- } \\
\text { Padrão }\end{array}$ & $\%$ D.P. \\
\hline 600 & 3570547,67 & 91,78 & $65.500,08$ & 1,83 \\
\hline 530 & 2999810,00 & 91,50 & $30.359,27$ & 1,01 \\
\hline 460 & 2518487,33 & 93,11 & $9.920,01$ & 0,39 \\
\hline 390 & 2167686,67 & 93,39 & $6.431,20$ & 0,30 \\
\hline 320 & 1717225,33 & 83,83 & $10.835,99$ & 0,63 \\
\hline
\end{tabular}

$\mathrm{Y}=-387867,57209+32419,77144 \mathrm{X}$, em que Y é a área correspondente ao sorgoleone no cromatograma (UV-280 $\mathrm{nm}$ ) e X, a concen-

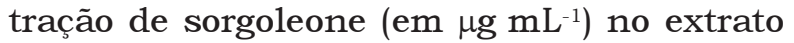
bruto.

O sorgoleone foi associado ao componente principal da fração, que apresentou um pico de absorção no ultravioleta em 8,4 min.

\section{Armazenamento de extratos}

Os extratos foram obtidos conforme descrito, a partir de três repetições de raízes recém-coletadas de 25 plântulas do acesso de sorgo BR 007A. Após a secagem dos extratos, os frascos foram tampados, protegidos da luz e armazenados em freezer $\left(-20^{\circ} \mathrm{C}\right)$. Foram analisados sete períodos de armazenamento $(0,1,3,5,7,14$ e 21 dias).

Os extratos foram diluídos em metanol até se atingir uma concentração próxima de $0,23 \mathrm{mg} \mathrm{mL}^{-1}$ e, em seguida, sonicados por 5 min para sua completa diluição. Foi recolhida uma fração de $1 \mathrm{~mL}$ por extrato diluído, que foi filtrada em Unidade Filtrante (Millex Lcr 0,45 micrometros, membrana de politetrafluoretileno (Ptfe) modificado, $\mathrm{P} / \mathrm{Sol}$. Orgânicas/Aquosas, $13 \mathrm{~mm}$, não estéril) e depois colocada em vials para a injeção em HPLC, como descrito anteriormente. A partir da área do pico de sorgoleone para cada extrato e da equação da curva de calibração, foram calculadas a quantidade de sorgoleone $\left(\mu \mathrm{g} \mathrm{mL}^{-1}\right)$ presente no extrato bruto e a quantidade de sorgoleone ( $\mathrm{mg} \mathrm{g}^{-1}$ de massa fresca de raiz), sendo este o dado final considerado para avaliar a produção de sorgoleone.

\section{Armazenamento de raizes}

Para quantificação de sorgoleone em extratos obtidos a partir de raízes armazenadas, foram considerados os mesmos períodos do experimento de armazenamento de extratos (0, 1, 3, 5, 7, 14 e 21 dias). Após serem destacadas da parte aérea, três repetições de 25 raízes foram acondicionadas em vidro âmbar de $40 \mathrm{~mL}$, que foram tampados e colocados em freezer $\left(-20^{\circ} \mathrm{C}\right)$. Imediatamente após a sua retirada do freezer, as raízes foram submetidas à extração. Posteriormente, os extratos foram analisados em HPLC, como descrito anteriormente.

\section{Análise Estatística}

Os dados foram submetidos a testes estatísticos paramétricos, por apresentarem normalidade pelo teste de Shapiro-Wilk e homogeneidade pelo teste de Brown-Forsythe, realizados no software JMP 5 (SAS Institute Inc.). Foi utilizado o teste ANOVA, seguido de Tukey a $5 \%$ de significância. 


\section{RESULTADOS E DISCUSSÃO}

\section{Obtenção do padrão}

A fração arroxeada coletada no fracionamento do extrato foi identificada por Ressonância Magnética Nuclear de Hidrogênio e de Carbono-13 (RMN de ${ }^{\circ} \mathrm{H}$ e de ${ }^{13} \mathrm{C}$ ) (Dayan et al., 2003; Kagan et al., 2003) como sorgoleone (Figuras 2, 3 e 4), sendo utilizado como o padrão para todos os experimentos.

\section{Armazenamento de extratos e de raizes}

É comum a utilização dos extratos das raízes do sorgo em testes de atividade e análise química após terem sido armazenados em baixas temperaturas (Einhelling \& Souza, 1992; Rasmussen et al., 1992; Nimbal et al., 1996; Souza et al., 1999; Kagan et al., 2003; Czarnota et al., 2003b; Hej1 \& Koster, 2004). Kagan et al. (2003) observaram, através de CCD, que extratos armazenados por uma semana $\mathrm{a}-20{ }^{\circ} \mathrm{C}$ apresentavam padrão e intensidade da banda de sorgoleone semelhantes aos dos extratos armazenados sob as mesmas condições por um período de três a oito meses. Entretanto, no estudo desenvolvido por Kagan et al. (2003) o sorgoleone não foi quantificado, não sendo possivel afirmar que não ocorre alteração quantitativa da substância durante o armazenamento.

A quantidade de extrato bruto das amostras utilizadas para posterior armazenamento variou de 3,51 a 4,81 $\mathrm{mg} \mathrm{g}^{-1}$ de massa fresca de raiz (MFR) (Tabela 2). A quantidade de sorgoleone obtido dos extratos armazenados por até 21 dias variou de 1,41 a $2,04 \mathrm{mg} \mathrm{g}^{-1}$ MFR, não sendo encontrada diferença significativa na quantidade final de sorgoleone obtida dos extratos armazenados.

O processo de extração do exsudato hidrofóbico ocorre a partir da imersão das raizes recém-coletadas em solução extratora com solvente apolar (Netzly \& Butler, 1986). O sorgoleone exsudado, presente na superficie dos pelos radiculares, fica retido nessa solução. Czarnota et al. (2003a) mostraram que o sorgoleone sintetizado no citoplasma dos pelos radiculares, antes de sua exsudação, permanece estocado no espaço entre a membrana plasmática e a parede celular. Portanto, maior quantidade de sorgoleone, além daquela presente na superficie dos pelos radiculares, poderia ser extraída caso a parede celular fosse rompida.

A submissão de tecidos vegetais a temperaturas de congelamento pode causar injúrias à parede celular (Olien \& Smith, 1977; Livingston \& Tallury, 2009). Além do dano fisico, podem ocorrer modificações na composição química da parede celular e na permeabilidade da membrana plasmática, que podem também influenciar na quantidade e qualidade do extrato final obtido (Palta et al., 1977; Olien \& Smith, 1977; Chen \& Gusta, 1978; Weiser et al., 1990; Murai \& Yoshida, 1998).

Foi observado que o congelamento das raízes não alterou significativamente a quantidade final de sorgoleone, quando comparada à obtida de raízes recém-coletadas. A quantidade de extrato e de sorgoleone obtidos das raízes armazenadas variou de 3,51 a $4,68 \mathrm{mg} \mathrm{g}^{-1}$ MFR e de 1,41 a $1,98 \mathrm{mg} \mathrm{g}^{-1}$ MFR, respectivamente (Tabela 3). Esse fato mostra que o congelamento e o armazenamento, mesmo que tenham causado danos às membranas e paredes celulares das raízes de sorgo, não interferiram na quantidade de sorgoleone extraído. Portanto, pode-se concluir que o sorgoleone não sofre degradação quando as raízes são mantidas a $-20{ }^{\circ} \mathrm{C}$ por até 21 dias. Em todos os trabalhos disponiveis, a extração de sorgoleone ocorreu imediatamente após a coleta das raízes. A possibilidade de armazenamento destas permite maior flexibilidade no planejamento dos experimentos, uma vez que a data de coleta não necessita coincidir com a data da extração.

Tabela 2 - Quantidade de extrato (mg g-1 MFR) do acesso BR 007A e de sorgoleone (SGL) após armazenamento do extrato ( $\mathrm{mg} \mathrm{g}^{-1} \mathrm{MFR}$ ) e percentual de sorgoleone no extrato (média \pm desvio-padrão)

\begin{tabular}{|c|c|c|c|}
\hline $\begin{array}{c}\text { Armazenamento } \\
\text { (dias) }\end{array}$ & Extrato & SGL & SGL (\%) \\
\hline 0 & $4,37 \pm 0,24$ & $1,70 \pm 0,01$ & $38,97 \pm 2,20$ \\
\hline 1 & $3,99 \pm 0,37$ & $1,54 \pm 0,16$ & $38,69 \pm 1,03$ \\
\hline 3 & $4,76 \pm 0,32$ & $1,97 \pm 0,16$ & $41,26 \pm 0,92$ \\
\hline 5 & $3,51 \pm 0,70$ & $1,56 \pm 0,36$ & $43,69 \pm 1,20$ \\
\hline 7 & $4,81 \pm 0,33$ & $2,04 \pm 0,21$ & $42,45 \pm 2,19$ \\
\hline 14 & $4,32 \pm 0,96$ & $1,77 \pm 0,43$ & $40,75 \pm 0,98$ \\
\hline 21 & $3,69 \pm 0,30$ & $1,41 \pm 0,11$ & $38,50 \pm 3,53$ \\
\hline
\end{tabular}




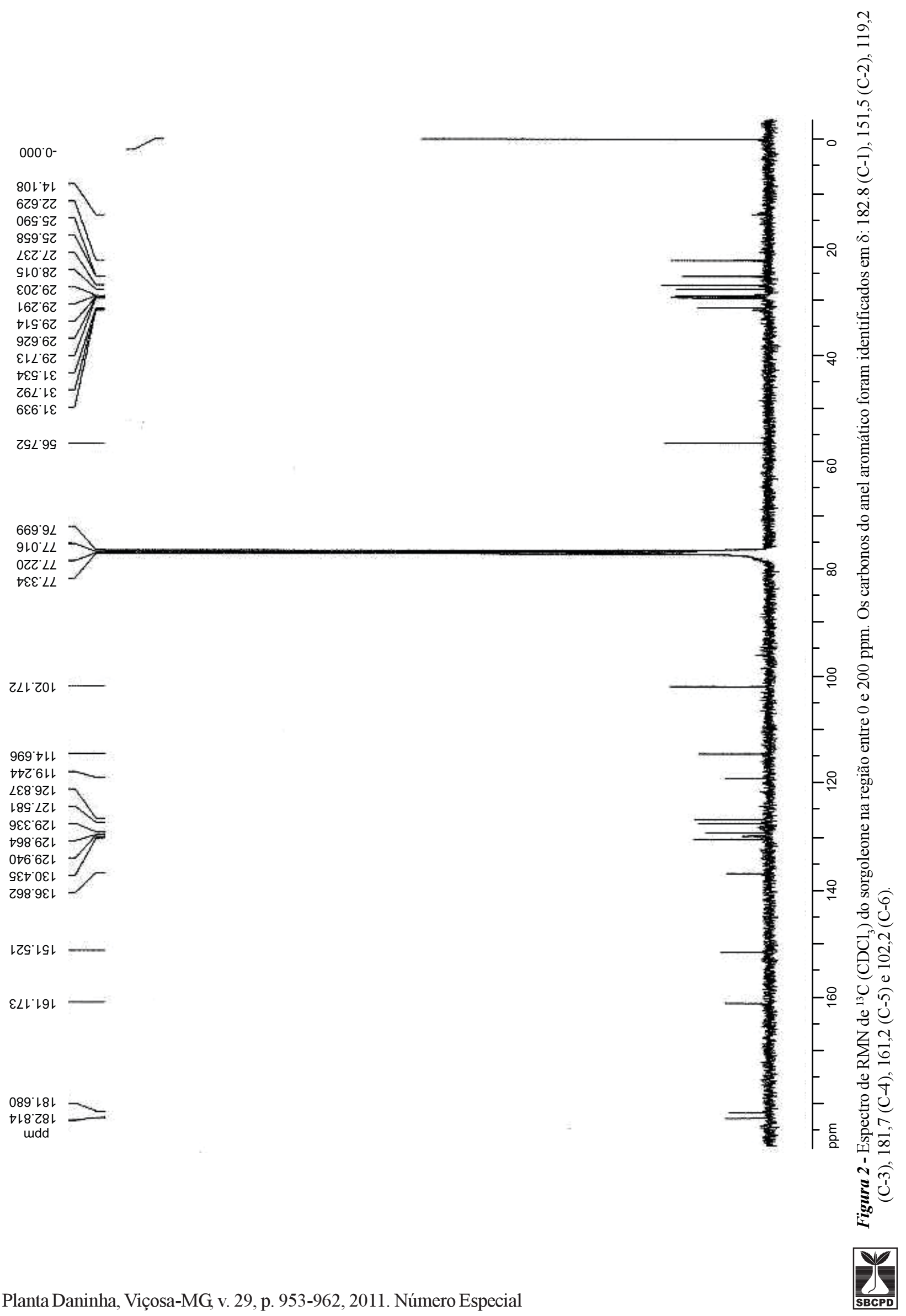




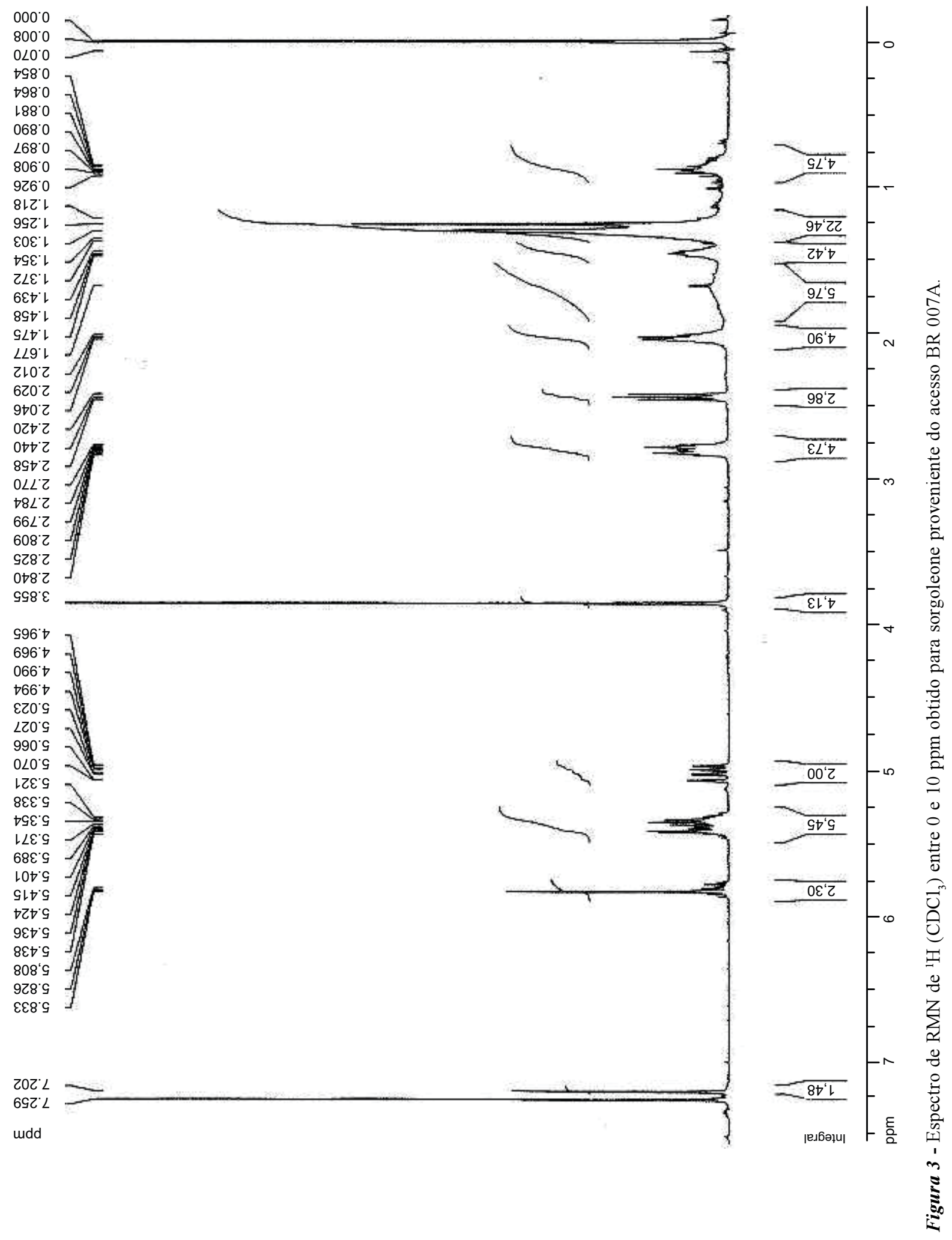



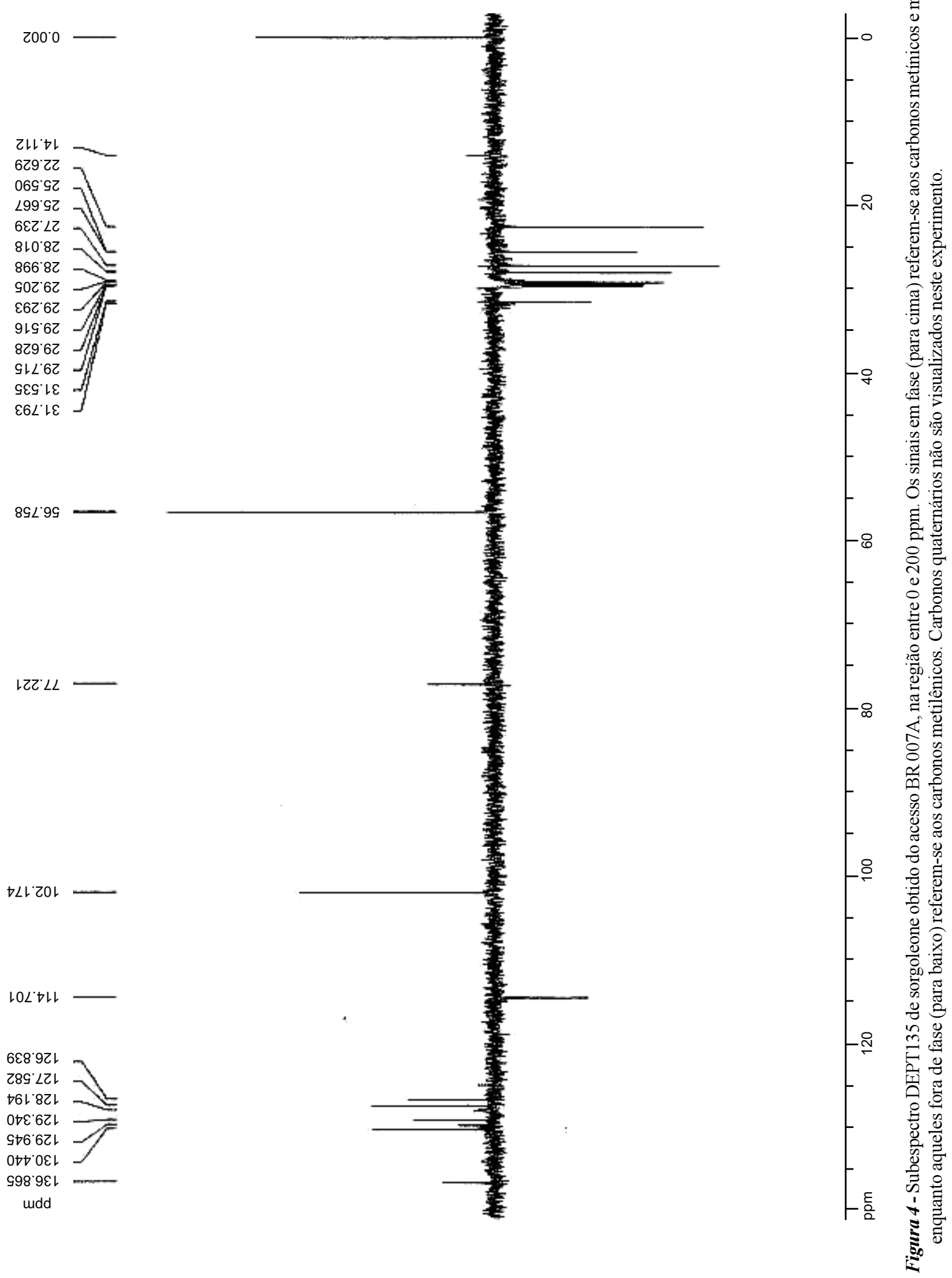
Tabela 3 - Quantidade de extrato e de sorgoleone (SGL) (mg g${ }^{1}$ MFR) do acesso BR 007A obtida de raízes armazenadas a $-20{ }^{\circ} \mathrm{C}$ antes da extração (média \pm desvio-padrão)

\begin{tabular}{|c|c|c|c|}
\hline $\begin{array}{c}\text { Armazenamento } \\
\text { (dias) }\end{array}$ & Extrato & SGL & \% SGL \\
\hline 0 & $4,37 \pm 0,24$ & $1,70 \pm 0,01$ & $38,97 \pm 2,20$ \\
\hline 1 & $4,06 \pm 0,54$ & $1,71 \pm 0,20$ & $42,08 \pm 0,63$ \\
\hline 3 & $4,68 \pm 0,58$ & $1,98 \pm 0,26$ & $42,34 \pm 0,78$ \\
\hline 5 & $3,51 \pm 0,10$ & $1,41 \pm 0,05$ & $40,24 \pm 0,60$ \\
\hline 7 & $4,31 \pm 0,17$ & $1,80 \pm 0,19$ & $41,75 \pm 3,18$ \\
\hline 14 & $4,17 \pm 0,63$ & $1,64 \pm 0,27$ & $39,17 \pm 0,58$ \\
\hline 21 & $3,54 \pm 0,30$ & $1,48 \pm 0,24$ & $41,79 \pm 3,42$ \\
\hline
\end{tabular}

Uma vez que o sorgoleone pode interferir no desenvolvimento de outras plantas e possui potencial para utilização no desenvolvimento de novos produtos naturais, como bio-herbicidas, é essencial investigar as condições favoráveis à sua produção, bem como para o processo de extração e armazenamento. Os resultados deste estudo mostraram que é possivel armazenar as raízes antes da extração e os extratos por até 21 dias a $-20^{\circ} \mathrm{C}$.

\section{AGRADECIMENTOS}

Ao Dr. J.A.S. Rodrigues, pelas sugestões feitas ao manuscrito, e ao CNPq, pela bolsa de produtividade em pesquisa concedida a Q.S. Garcia.

\section{LITERATURA CITADA}

ALSAADAWI, I. S. et al. Allelopathic suppression of weed and nitrification by selected cultivars of Sorghum bicolor (L.) Moench. J. Chem. Ecol., v. 12, n. 1, p. 209-219, 1986.

CANNELL, R. J. P. Natural products isolation. New Jersey: Humana Press, 1998. 472 p.

CHANG, M. et al. Chemical regulation of distance: characterization of the first natural host germination stimulant for Striga asiatica. J. Am. Chem. Soc., v. 108, n. 24, p. $7858-7860,1986$

CHEN, P. M.; GUSTA, L. V. Changes in membrane permeability of winter wheat cells following freeze-thaw injury as determined by nuclear magnetic resonancel. Plant Physiol., v. 61, n. 6, p. 878-882, 1978.

CORREIA, N. M.; SOUZA, I. F.; KLINK, U. P. Palha de sorgo associada ao herbicida imazamox no controle de plantas daninhas na cultura da soja em sucessão. Planta Daninha, v. 23 , n. 3 , p. $483-489,2005$.
CZARNOTA, M. A. et al. Anatomy of sorgoleone-secreting root hairs of Sorghum species. Inter. J. Plant Sci., v. 164, n. 4, p. 861-866, 2003a.

CZARNOTA, M. A.; RIMANDO, A. M.; WESTON, L. A Evaluation of root exudates of seven sorghum accessions. J. Chem. Ecol., v. 29, n. 9, p. 2073-2083, 2003 b.

DAYAN, F. E.; KAGAN, I. A.; RIMANDO, A. M. Elucidation of the biosynthetic pathway of the allelochemical sorgoleone using retrobiosynthetic nmr analysis. J. Biol. Chem., v. 278, n. 31, p. 28607-28611, 2003.

DAYAN, F. E. et al. Sorgoleone. Phytochemistry, v. 71, n. 10, p. 1032-1039, 2010.

EINHELLIG, F. A.; RAMUSSEN, J. A. Prior cropping with grain Sorghum inhibits weeds. J. Chem. Ecol., v. 15, n. 2, p. 951-960, 1989.

EINHELLIG, F. A.; SOUZA, I. F. Phytotoxicity of sorgoleone found in grain sorghum root exudates. J. Chem. Ecol., v. 18, n. 1, p. 1-11, 1992.

GUENZI, W. D.; MCCALLA, T. M.; NORDSTADT, F. A. Presence and persistence of phytotoxic substances in wheat, oat, corn and sorghum residues. Agron. J., v. 59, n. 2, p. 163-165, 1967.

HEJ, A. M.; KOSTER, K. L. The allelochemical sorgoleone inhibits root H+ATPase and water uptake. J. Chem. Ecol., v. 30, n. 11, p. 2181-2191, 2004.

KAGAN, I. A.; RIMANDO, A. M.; DAYAN, F. E. Chromatographic separation and in vitro activity of sorgoleone congeners from the roots of Sorghum bicolor. J. Agric. Food Chem., v. 51, n. 26, p. 7589-7595, 2003.

LEHLE, F. R.; PUTNAM, A. R. Allelopathic potential of sorghum (Sorghum bicolor): isolation of seed germination inhibitors. J. Chem. Ecol., v. 9, n. 8, p. 1223-1234, 1983.

LIVINGSTON, D. P.; TALLURY, S. P. Freezing in nonacclimated oats. II: Thermal response and histology of recovery in gradual and rapidly frozen plants. Therm. Acta, v. 481, n. $1-2$, p. $20-27,2009$.

MAGALHÃES, P. C.; DURÃES, F. O. M.; RODRIGUES, J. A. S. Cultivo de sorgo - ecoficiologia. Sete Lagoas: Embrapa Milho e Sorgo, 2009. (Sistemas de Produção, 2)

MURAI, M.; YOSHIDA, S. Evidence for the cell wall involvement in temporal changes in freezing tolerance of jerusalem artichoke (Helianthus tuberosus L.) tubers during cold acclimation. Plant Cell Physiol., v. 39, n. 1, p. 97-105, 1998. 
NETZLY, D. H.; BUTLER, L. G. Roots of sorghum exude hydrophobic droplets containing biologically active components. Crop Sci., v. 26, n. 4, p. 775-778, 1986.

NETZLY, D. H. et al. Germination stimulants of witchweed (Striga asiatica) from hydrophobic root exudate of sorghum (Sorghum bicolor). Weed Sci., v. 36, n. 4, p. 441-446, 1988.

NIMBAL, C. I. et al. Herbicidal activity and site of action of the natural product sorgoleone. Pestic. Biochem. Physiol., v. 54, n. 1, p. 73-83, 1996.

OLIBONE, D. et al. Crescimento inicial da soja sob efeito de resíduos de sorgo. Planta Daninha, v. 24, n. 2, p. 255-261, 2006.

OLIEN, C. R.; SMITH, M. N. Ice adhesions in relation to freeze stress. Plant Physiol., v. 60, n. 4, p. 499-503, 1977.

PALTA, J. P.; LEVNRT, J.; STADELMANN, E. J. Freezing injury in onion bulb cells. II Post-thawing injury or recovery. Plant Physiol., v. 60, n. 3, p. 398-401, 1977.

PANASIUK, O.; BILLS, D. D.; LEATHER, G. R. Allelopathic influence of Sorghum bicolor on weeds during germination and early development of seedlings. J. Chem. Ecol., v. 12, n. 6, p. 1533-1543, 1986

RASMUSSEN, J. A. et al.. Sorgoleone from root exudates inhibits mitochondrial functions. J. Chem. Ecol., v. 18, n. 2, p. 197-207, 1992.

RODRIGUES, J. A. S. Cultivo de sorgo - Apresentação. Sete Lagoas: Embrapa Milho e Sorgo, 2009. (Sistemas de Produção, 2)
SOUZA, C. N.; SOUZA, I. F.; PASQUAL, M. Extração de sorgoleone sobre o crescimento de plantas. Ci. Agrotec. v. 23 , n. 2 , p. $331-338,1999$.

SRIVASTAVA, A. et al. Effect of storage conditions on the biological activity of phenolic compounds of blueberry extract packed in glass bottles. J. Agric. Food Chem., v. 55, n. 7, p. 2705-2713, 2007.

TABART, J. et al. Optimisation of extraction of phenolics and antioxidants from black currant leaves and buds and of stability during storage. Food Chem., v. 105, n. 3, p. $1268-1275,2007$

TARDIN, F. D.; RODRIGUES, J. A. S.; COELHO, R. R. Cultivo de sorgo - Cultivares. Sete Lagoas: Embrapa Milho e Sorgo, 2009. (Sistemas de Produção, 2)

TREZZI, M. M.; VIDAL, R. A.; KRUSE, N. D. Fitotoxicidade de extratos hidrofóbicos e hidrofílicos de sorgo e milheto. R. Ci. Agrovet., v. 4, n. 1, p. 25-34, 2005 a.

TREZZI, M. M. et al. Purificação e identificação de sorgoleone e sua quantificação em genótipos de sorgo (Sorghum bicolor L. Moench). Pesticidas: R. Ecotoxicol. Meio Amb., v. 15, p. 105-112, 2005b.

UDDIN, M. R. et al. Enhancing sorgoleone levels in grain sorghum root exudates. J. Chem. Ecol., v. 36, n. 8, p. $914-922,2010$.

WEISER, R. L.; WALLNER, S. J.; WADDELL, J. W. Cell wall and extensin mRNA changes during cold acclimation of pea seedlings. Plant Physiol., v. 93, n. 3, p. 1021-1026, 1990 . 